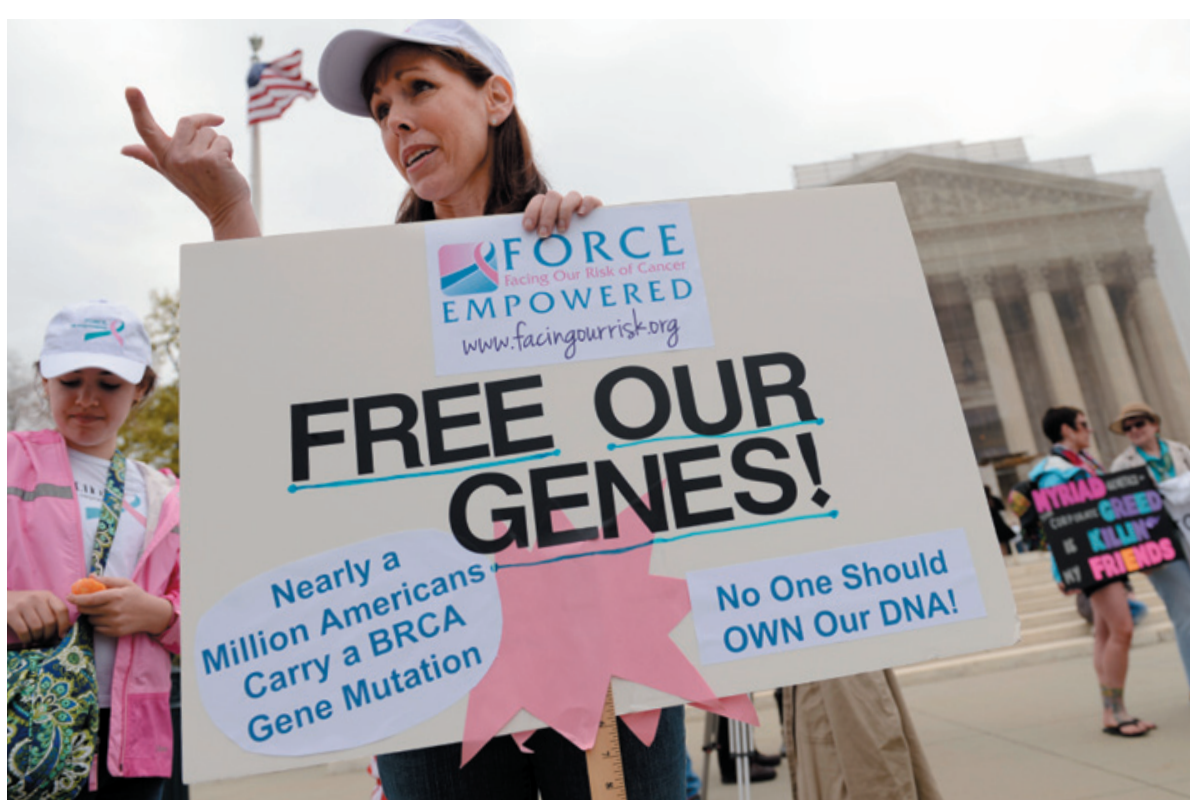

Demonstrators protest against gene patenting outside the US Supreme Court last April.

\title{
GENETICS
}

\section{Cancer-gene data sharing boosted}

\section{Efforts to get more breast-cancer gene variants into public databases are gaining ground.}

\section{BY ERIKA CHECK HAYDEN}

$\mathrm{W}$ hen the US diagnostics giant Myriad Genetics had its legal monopoly on breast-cancer gene testing eliminated one year ago, the company still retained an enormous edge over competitors. Although the US Supreme Court's ruling last June invalidated the patenting of genes, and with it Myriad's exclusive rights on two genes associated with breast- and ovarian-cancer risk, the firm still has a private trove of data from 1.3 million genetic tests.

That information gives Myriad, of Salt Lake City, Utah, an advantage in interpreting test results on these genes.

But a coalition of scientists, physicians, patients and genetic counsellors says that it will soon eliminate that advantage. A year after the Supreme Court invalidated the patenting of genes - and with it, Myriad's monopoly on testing for mutations in the $B R C A 1$ and BRCA 2 genes linked to breast and ovarian cancer - the number of entries for BRCA variants in ClinVar, a public database for clinical genetic data, has grown to around one-third of the number in the useful it becomes for interpreting the results of any individual gene test. Of the thousands of possible variations on the spelling of the DNA bases that make up the BRCA genes, only some will be linked to cancer. If a particular variant is significantly more frequent among those who develop cancer than in the general population, its contribution to disease risk can be calculated. Only by collecting data from many different people can scientists observe the same variants often enough to make these kinds of calculations with confidence.

"If Myriad holds the data hostage in a proprietary database, they're harming patients," says Sherri Bale, managing director of GeneDx in Gaithersburg, Maryland, one of several competitors being sued by Myriad for infringement of other patents associated with the BRCA tests. These companies have cut the price of $B R C A$ tests to an average of $\$ 2,200$ compared with Myriad's $\$ 4,040$ - and are contributing an accelerating flow of BRCA data to ClinVar, which is held at the National Center for Biotechnology Information in Bethesda, Maryland.

"All of these companies seem much more willing to share data," says genetic epidemiologist David Goldgar of the University of Utah's Huntsman Cancer Institute in Salt Lake City.

Geneticists such as Rehm and Robert Nussbaum at the University of California, San Francisco, are urging patients, genetics professionals and insurance companies to use only $B R C A$-testing companies that share data.

Geneticists have long exhorted their colleagues to share, but have been blocked by practical and competitive barriers. Sharing takes time and money, and geneticists fear compromising patient privacy or seeing competitors beat them to market or publication with results based on their own data. An initiative started by Nussbaum - the Sharing Clinical Reports Project — aims to bring about a sea change by coaxing clinical labs to deposit the results of Myriad diagnostic tests into ClinVar.

ClinVar now holds information on 5,752 BRCA variants, deposited by Sharing Clinical Reports, Myriad competitors and academic labs, compared with Myriad's 16,000. And other, broader, plans for data sharing are afoot. At a meeting in London in March, geneticists and physicians convened by the non-profit Global Alliance for Genomics and Health, based in Toronto, Canada, which promotes data sharing, outlined a plan to create an even more extensive data resource. Dubbed the $B R C A$ Challenge, it would link major clinicalgenetics databases such as ClinVar and the Leiden Open Variation Database, funded by the European Union and run by a team in the Netherlands.

"The thought," Goldgar says, "is that the rest of the world has roughly the same amount of data as Myriad - and if we put it all together and make a concerted effort to try to use it, then we can be on equal footing." - 